\title{
HumanComfort Modelica-Library Thermal Comfort in Buildings and Mobile Applications
}

\author{
Boris Michaelsen Joerg Eiden \\ XRG Simulation $\mathrm{GmbH}$ \\ Harburger Schlossstr. 6-12, 21079 Hamburg, Germany \\ \{michaelsen,eiden\}@xrg-simulation.de
}

\section{Abstract}

The HumanComfort library provides basic models to predict the thermal comfort of occupants within an airconditioned space in mobile or stationary applications. The library is modularly structured to allow a flexible use in combination with air conditioning systems or complex zone simulations. The HumanComfort library provides models and functions to establish a multi zone model to analyse the interaction between the inertia of the zone and a HVAC (heating ventilation and air conditioning) system relating to the thermal comfort of the occupants. The validation of the building simulation including a thermal comfort analysis was done by a comparative validation test with EnergyPlus using DesingBuilder [1].

Keywords: human comfort, thermal comfort, PMV, PPD, GTO, multi zone model

\section{Introduction}

Energy systems are often optimized with regard to economical rules, on the other hand humans feel comfortable within certain limits defined by thermal and personal factors. Studies showed that the change of the thermal sensations can be defined by means of characteristic numbers and standardized mathematical methods. The HumanComfort library is currently developed within the European research project EuroSysLib-D, providing basic models to predict the human comfort in form of mathematical criteria and also graphical visualizations. The HumanComf ort library uses an integrated approach to simulate a zone (building or cabin model) and an air-conditioning simultaneously. This approach is crucial for the optimal dimensioning of an air conditioning system by taking the thermal comfort into account.

\section{Library Structure}

The main structure of the HumanComfort library is shown in fig. 1.

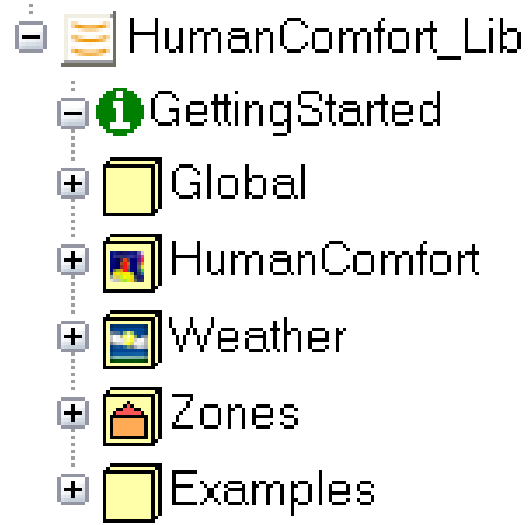

Figure 1: HumanComf ort library structure

The GettingStarted package includes a brief introduction of the library concept and shows the most important steps to handle the library.

The Global package encloses common models and functions, icons, interfaces, and special types.

The HumanComfort package contains basic functions and models to predict the thermal comfort. It also contains a package for the model animation of the characteristic numbers.

The Weather package encloses functions and models to provide annual weather data for the zone model.

The Zone package provides models for stationary and mobile applications. Mobile applications will be covered by models for aircraft and automotive cabins. The mobile zones are designed as detailed as necessary to analyse the human comfort. It is not the aim of the mobile zones to cover up all effects in detail.

The Examples package includes examples for typical applications and verification models. 


\section{Human Comfort}

Thermal comfort is defined as that condition of mind that expresses satisfaction with the thermal environment. Dissatisfaction may be caused by warm or cool discomfort of the body or may be caused by an unwanted cooling or heating [2]. Thermal comfort standards are based on collected data from laboratory and field studies which provide the necessary statistical data to define the conditions that a specified percentage of occupants will find thermally comfortable.

The implemented thermal prediction models consider statistic and adaptive comfort models, based on the following standards:

- DIN EN ISO 7730 [2]

- ASHRAE Standard 55-2004 [3]

- ISSO 74 [4]

To predict the thermal comfort, it is necessary to consider the thermal factors: temperature, radiant temperature, humidity, and air velocity as well as the personal factors: activity (metabolic rate) and clothing insulation.

The relation between this factors are provided by the standards as mathematical formulated characteristic numbers.

Using the characteristic numbers Predicted Mean Vote (PMV) and Predicted Percentage of Dissatisfied (PPD) the thermal comfort can be calculated.

The local thermal discomfort will be considered by the Percentage of Discomfort (PD) and can be divided into the following sections:

- Radiant temperature asymmetry

- Draft

- Vertical air temperature difference

- Cool or warm wall

- Cool or warm ceiling

- Cool or warm floors

Adaptive thermal comfort consider the fact that occupants will tolerate a wider range of temperatures and internal conditions when more control is allowed over their internal environment. The implementation of the ISSO 74 (Dutch Thermal Comfort Guideline) expands the HumanComf ort library with additional characteristic numbers and diagrams regarding the adaptive thermal comfort.

The operative indoor temperature, the Adaptive Temperature Limits (ATG) and the annual characteristic numbers Weighted Temperature Exceeding Hours
(GTO), $\mathrm{TO}^{\circ} 5^{\circ} \mathrm{C}$ and $\mathrm{TO} 28^{\circ} \mathrm{C}$ (Operative Temperature Limits) cover up this adaptive thermal comfort.

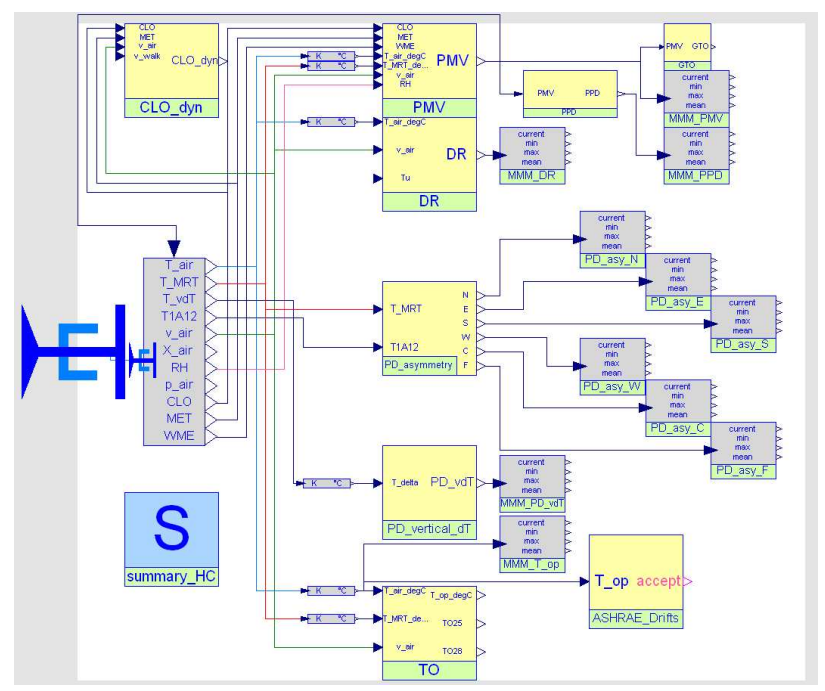

Figure 2: Diagram layer of the HumanComf ort model; including the functions and models for the PMV, PPD, and PD's calculation, and the HumanComfort adapter

The characteristic numbers are pooled in one model named HumanComfort (see fig. 2). The therefore established HumanComfort adapter enables an easy interface for the end-user. This allows a complete thermal comfort analysis by simply connecting the HumanComf ort model to this adapter.

\subsection{Characteristic Numbers}

Calculation methods and the resulting characteristic numbers are provided in several international standards ([2], [3], [4]). The characteristic numbers are implemented as functions and models for a flexible use. The most important characteristic numbers are described in detail in the following sections.

\subsubsection{Predicted Mean Vote (PMV)}

The PMV is an index that predicts the mean value of the votes of a large group of persons on the sevenpoint thermal sensation scale [3]. It uses heat balance principles to relate the thermal and personal factors for thermal comfort to the average response of people on the sensation scale. The ideal range is between -0.5 and +0.5 (neutral) (see fig. 3). 


$\begin{array}{cc}\text { PMV } & \text { Comfort } \\ +3 & \text { hot } \\ +2 & \text { warm } \\ +1 & \text { slightly warm } \\ 0 & \text { neutral } \\ -1 & \text { slightly cool } \\ -2 & \text { cool } \\ -3 & \text { cold }\end{array}$
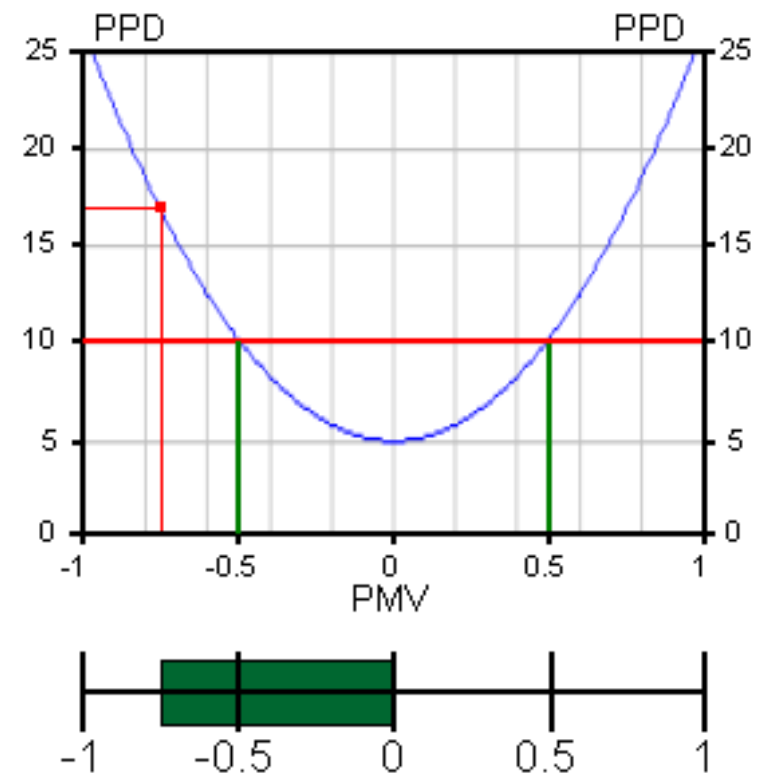

Figure 3: PMV and PPD visualization, screen shot of the Dymola model animation window

$$
\begin{array}{lll}
P M V & =\text { Predicted Mean Vote } & {[-]} \\
P P D & =\text { Predicted Percentage of Dissatisfied } & {[\%]}
\end{array}
$$

Thermal factors:

$$
\begin{array}{lll}
T_{a} & =\text { ambient temperature } & {[\mathrm{K}]} \\
T_{r}=\text { mean radiant temperature } & {[\mathrm{K}]} \\
v_{\text {air }}=\text { relative air velocity } & {[\mathrm{m} / \mathrm{s}]} \\
p_{a}=\text { water vapour pressure } & {[\mathrm{Pa}]} \\
R H & =\text { relative humidity } & {[\%]}
\end{array}
$$

Personal factors:

$$
\begin{aligned}
& C L O=\text { thermal isolation of the clothing }\left[\mathrm{clo}=0.155 \cdot \mathrm{m}^{2} \cdot \mathrm{K} / \mathrm{W}\right] \\
& M=\text { metabolic rate } \\
& W=\text { external work } \\
& {\left[\mathrm{met}=58.15 \mathrm{~W} / \mathrm{m}^{2}\right]} \\
& {\left[\mathrm{W} / \mathrm{m}^{2}\right]}
\end{aligned}
$$

Internal values of PMV function:

$$
\begin{aligned}
& I_{c l}=\text { thermal resistance of the clothing } \\
& h_{c}=\text { convective heat transfer coefficient } \\
& f_{c l}=\text { ratio of clothed body } \\
& H L_{x}=\text { heat loss factors } \\
& T S=\text { thermal sensation transformation coefficient }
\end{aligned}
$$

The first step to determine PMV is the calculation of the thermal resistance of the clothing $I_{c l}$ and the ratio of clothed body $f_{c l}$ (see eq. 1 and 2).

$$
\begin{gathered}
I_{c l}=0.155 \cdot C L O \\
f_{c l}=\left\{\begin{array}{lll}
1.05+0.645 \cdot I_{c l} & \text { for } \quad I_{c l}>0.078 \\
1+1.29 \cdot I_{c l} & \text { for } \quad & I_{c l} \leq 0.078
\end{array}\right.
\end{gathered}
$$

It is necessary to iterate, due to $h_{c}=f\left(T_{c l}\right)$ and $T_{c l}=$ $f\left(h_{c}, T_{c l}\right)$, see eq. 3 and 4 . The allowed failure of the iteration process is $10^{-9}$.

$$
\begin{aligned}
& h_{c}= \begin{cases}2.38 \cdot\left|T_{c l}-T_{a}\right|^{\frac{1}{4}} & \text { for } \quad 2.38 \cdot\left|T_{c l}-T_{a}\right|^{\frac{1}{4}}>12.1 \cdot \sqrt{v_{\text {air }}} \\
12.1 \cdot \sqrt{v_{\text {air }}} & \text { for } \quad 2.38 \cdot\left|T_{c l}-T_{a}\right|^{\frac{1}{4}} \leq 12.1 \cdot \sqrt{v_{\text {air }}}\end{cases} \\
& \begin{aligned}
T_{c l}= & 35.7-0.028 \cdot(M-W) \\
& -I_{c l} \cdot\left[3.96 \cdot 10^{-8} \cdot f_{c l} \cdot\left(T_{c l}^{4}-T_{r}^{4}\right)+f_{c l} \cdot h_{c} \cdot\left(T_{c l}-T_{a}\right)\right]
\end{aligned}
\end{aligned}
$$

The user has two options to describe the input of the humidity. The first one is to use the water vapour pressure $p_{a}$. The second option is to use the relative humidity $R H$. The following equation describes the relation between $p_{a}$ and $R H$.

$$
p_{a, \text { internal }}=\left\{\begin{array}{ccc}
R H \cdot 10 \cdot e^{16.6536-4030.183 /\left(t_{a}+235\right)} & \text { for } & p_{a}=0 \\
p_{a} & \text { for } & p_{a}>0
\end{array}\right.
$$

The calculations of all heat losses and the thermal sensation transformation coefficient are the last steps to determine the PMV (see eq. 6 to 12).

$$
\begin{gathered}
T S=\left[0.303 \cdot e^{-0.036 \cdot M}+0.028\right] \\
H L_{1(\text { skin })}=3.05 \cdot 0.001 \cdot\left(5733-6.99 \cdot(M-W)-P_{a}\right) \\
H L_{2(\text { sweat })}=\left\{\begin{array}{cc}
0.42 \cdot(M-W-58.15) & \text { for } \quad M-W>58.15 \\
0 & \text { for } \quad M-W \leq 58.15
\end{array}\right. \\
H L_{3(\text { latent_respiration })}=1.7 \cdot 0.00001 \cdot M \cdot\left(5867-p_{a}\right) \\
H L_{4(\text { dry_respiration })}=0.0014 \cdot M \cdot\left(34-t_{a}\right) \\
H L_{5(\text { radiation })}=3.96 \cdot 0.00000001 \cdot f_{c l} \cdot\left(T_{c l}^{4}-T_{r}^{4}\right) \\
H L_{6(\text { convection })}=f_{c l} \cdot h_{c} \cdot\left(t_{c l}-t_{a}\right)
\end{gathered}
$$

The final step is the calculation of the PMV.

$P M V=T S \cdot\left(M-W-H L_{1}-H L_{2}-H L_{3}-H L_{4}-H L_{5}-H L_{6}\right)$

The PMV is the basis of the PPD and the GTO.

\subsubsection{Predicted Percentage of Dissatisfied (PPD)}

The PPD is an index that establishes a quantitative prediction of the percentage of thermally dissatisfied people determined from PMV (see eq. 14 and fig. 4) [3].

$$
P P D=100-95 \cdot e^{-0.03353 \cdot P M V^{4}-0.2179 \cdot P M V^{2}}
$$




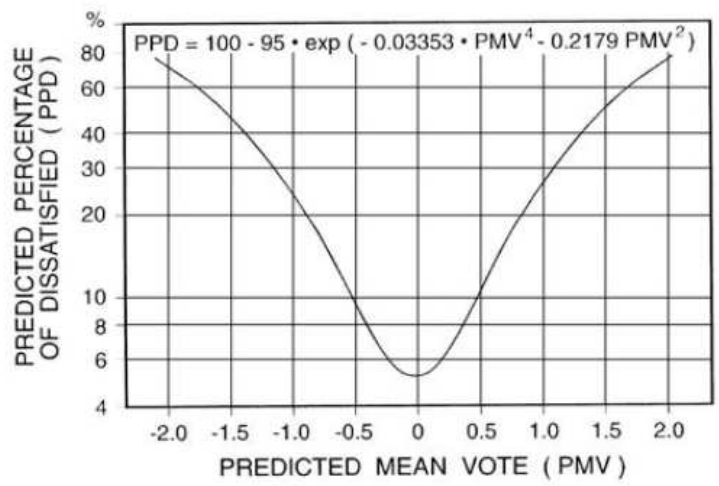

Figure 4: Correlation between PMV and PPD

\subsubsection{Weighted Temperature Exceeding Hours (GTO)}

The GTO-method which is based on the analytical PMV model is an annual characteristic number.

In the GTO-method the hours during which the calculated or actual PMV exceeds the PMV-limit of +0.5 are weighted proportional to the PPD. With this, a temperature that results in a PPD of $20 \%$ during 1 hour will be weighted twice as severe as a temperature that results in $10 \%$ dissatisfied occupants [4]. When the PMV has a value of $0.5(\mathrm{PPD}=10)$ the weighting factor is 1.0 , see tab. 1 :

\begin{tabular}{|c|c|c|}
\hline PMV & PPD & Weighting factor \\
\hline \hline 0 & 5 & 0.0 \\
\hline 0.5 & 10 & 1.0 \\
\hline 0.7 & 15 & 1.5 \\
\hline 1.0 & 26 & 2.6 \\
\hline
\end{tabular}

Table 1: Correlation of PMV, PPD, and the GTO weighting factor [4]

The GTO will be calculated every 3600 seconds, by using the actual PMV value as the input. This is implemented by using the Modelica sample function, see source code 1 . The governing equations for the GTO are described in eq. 15- 17.

$$
\begin{gathered}
P P D_{\text {hour }}=100-95 \cdot e^{-0.03353 \cdot P M V_{\text {hour }}^{4}-0.2179 \cdot P M V_{\text {hour }}^{2}} \\
\text { GTO } O_{\text {hour }}=\left\{\begin{array}{cll}
\frac{P P D_{\text {hour }}}{10} & \text { for } & P M V \geq 0.5 \\
0 & \text { for } & P M V<0.5
\end{array}\right. \\
\text { GTO }=\sum_{\text {hour }=1}^{8760} \text { GTO } O_{\text {hour }}
\end{gathered}
$$

$$
\begin{aligned}
& P M V_{\text {hour }}=\text { Predicted Mean Vote of current hour } \\
& P P D_{\text {hour }}=\text { Predicted Percent. of Dissatisfied of curr. hour } \\
& G T O_{\text {hour }}=\text { Weighted temperature of current hour } \\
& G T O=\text { Weighted temperature Exceeding Hours }
\end{aligned}
$$

The following source code shows the implementation of the GTO-Method in Modelica.

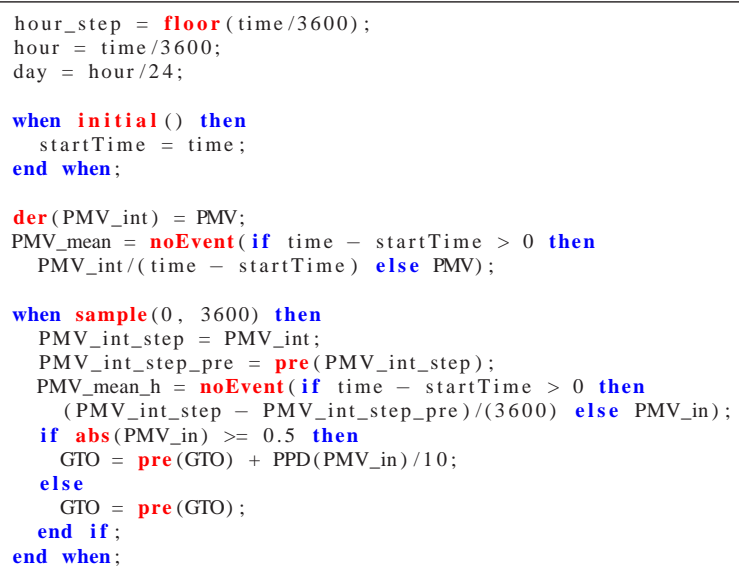

Source Code 1: Modelica code of the GTO model

The in [4] given annual limit of 150 will be considered in the analyses of the GTO. Fig. 5 describes the correlation between the hourly values of PMV, PPD and GTO. In this theoretical case the PMV increase from -3 to +3 in a time period of $60 \mathrm{~h}$. The grey area in the graph shows a constant GTO value within the PMV limit from -0.5 to +0.5 .

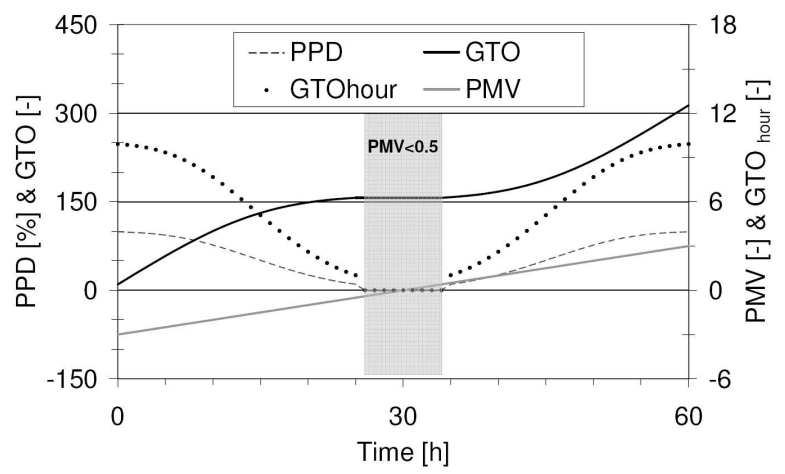

Figure 5: Correlation of the hourly values of PMV, PPD, and GTO by an increasing PMV from -3 to +3

\subsection{Other Characteristic Numbers}

The following characteristic numbers are defined in the standards and are implemented in the HumanComfort library, but will not be described in this paper in detail.

- DR - Draught Rating [2]

- PD Due to Radiant Asymmetry [2]

- PD Due to Cool Wall

- PD Due to Warm Wall 
- PD Due to Cool Ceiling

- PD Due to Warm Ceiling

- PD Due to Cool or Warm Floors [2]

- PD Due to Vertical Air Temperature Difference [2]

- ATG - Adaptive Temperature Limits [4]

- TO - Operative Temperature Limits [4]

- DAR - Limits on Temperature Drifts and Ramps [3]

\section{Zones}

The zones are separated into models for mobile and stationary applications. The stationary applications are single rooms or small buildings. The mobile applications will be automotive or aircraft cabins. Each application can be combined with the weather or HumanComfort module (see fig. 6).

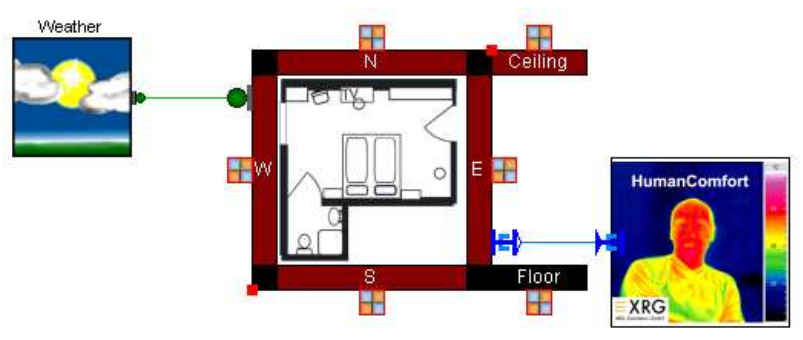

Figure 6: One room model with a connected weather and HumanComfort model

The main features of the zone models are:

Internal heat radiation between visible surfaces. The RadiationExchangeApproximated model considers the heat exchange due to heat radiation of surfaces to each other. The external solar radiation through the windows and the internal heater radiation will be considered as well. Therefore the heat emissions of all surfaces, defined by their areas, temperatures and long wave emissions coefficients will be collected in a virtual heat pool. The solar radiation, defined by the short wave emission coefficient, and the heater radiation are also collected in the virtual heat pool. The absorbed heat flows of the surfaces are defined by their areas, temperatures and absorption coefficients. The schematic of the virtual heat pool is shown in fig. 7.

The solar radiation reflection and back reflection on all surfaces will affect the final amount of the solar radiation into the virtual heat pool. The mean absorption rate of a zone is calculated with the absorption ratio of

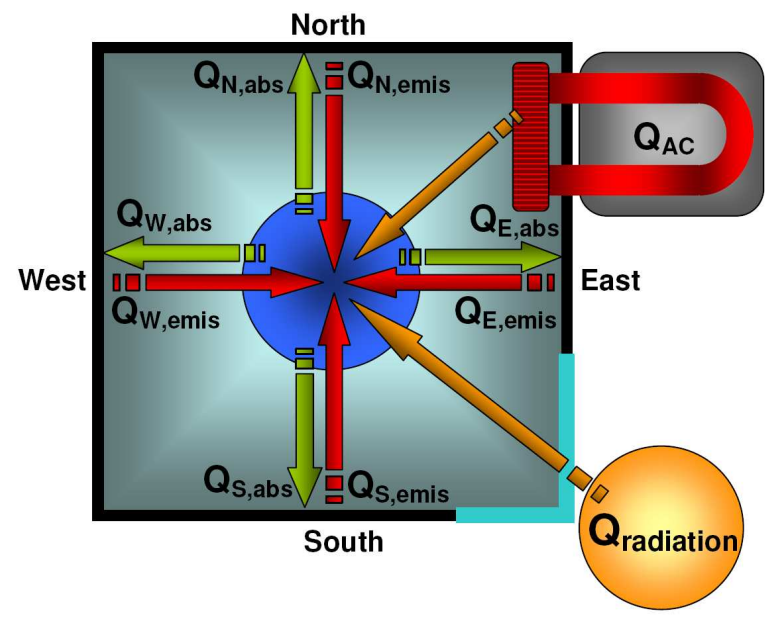

Figure 7: Schematic of the virtual heat pool implemented in the RadiationExchangeApproximated model

all surfaces and a reflection parameter. The reflection parameter defines the mean number of internal reflections of all sun rays, before they leave the zone. The source code 2 presents the implementation of the solar reflection calculation.

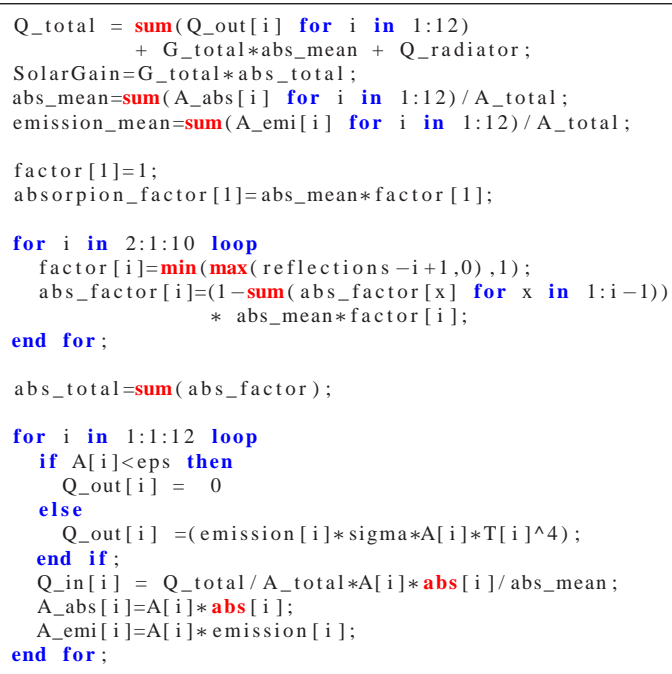

Source Code 2: Modelica code of the solar refection.

This virtual heat pool method is an approximation of the exact calculation of the heat radiation exchange. To prove the HumanComfort approach, the model was validated against the EnergyPlus program, which uses the Hottel Grey Interchange Method. This method is an exact formulation of radiant heat transfer within an enclosure of grey diffuse surfaces [5].

The validation shows that the surface and mean radiant temperatures, calculated with the HumanComfort library, are within acceptable limits.

With regard to an annual simulation of a complex 
building, the approximated radiation model of the HumanComfort library provides a fast and sufficient method to determine the heat radiation exchange.

Control volume with energy and mass balance. The HumanComf ort library provides two control volumes. A ControlVolumeAir model for the indoor air with heat and flow ports, using the Modelica_Media moist air media model, and the ControlVolumeWater model for water flows in heating cycles, fitted to improve incompressible flows.

Multi-layer wall model. The wall models considers the heat conduction and convection at the in- and outside. The internal and external radiation absorption as well as the internal heat radiation will be considered. Every layer has a homogeneous mass to store thermal energy. It is also possible to define the orientation of the wall to the sun. The wall model input is a record which includes a parameter matrix. The parameters define the conductivity, thermal capacity, density, surface area, and thickness for every layer. The HumanComfort library contains severals pre-designed wall records, ready to use. In addition, it is possible to connect a heating system (e.g. floor heating) to a single layer in the wall model via heat flow connectors.

Air exchange due to pressure and density differences between adjacent rooms with doors or other openings. The WallFlowDensityPressure model defines the air exchange between two rooms. The mass flow rate depends on pressure and density differences and the size of the opening (see fig. 8). The opening size can be varied during the simulation to consider realistic office building behavior.

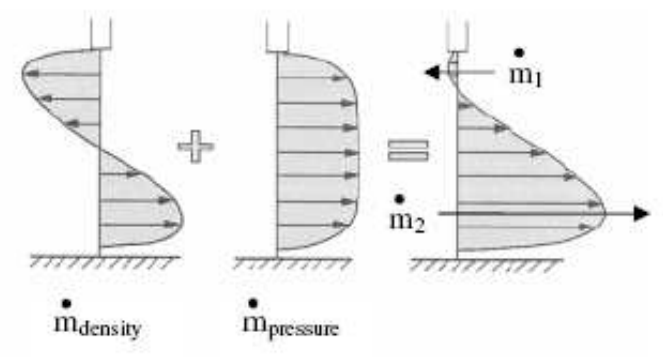

Figure 8: Influence of pressure and density for air exchange between two rooms [6]

The governing equation for the resulting mass flow rate are described as follows:

$$
\dot{m}_{\text {density }}=\frac{W}{3} \cdot H^{\frac{3}{2}} \cdot \mu_{0} \cdot \sqrt{g \cdot \frac{\Delta \rho}{\rho_{m}}} \cdot N o_{\text {doors }}
$$

$$
\dot{m}_{\text {pressure }}=\sqrt{\frac{\Delta p \cdot 2}{\rho_{m} \cdot \zeta}} \cdot \frac{W \cdot H \cdot \rho_{m} \cdot N o_{\text {doors }}}{2}
$$

$$
\dot{m}_{1}=\dot{m}_{\text {pressure }}-\dot{m}_{\text {density }}
$$

$$
\dot{m}_{2}=\dot{m}_{\text {pressure }}+\dot{m}_{\text {density }}
$$

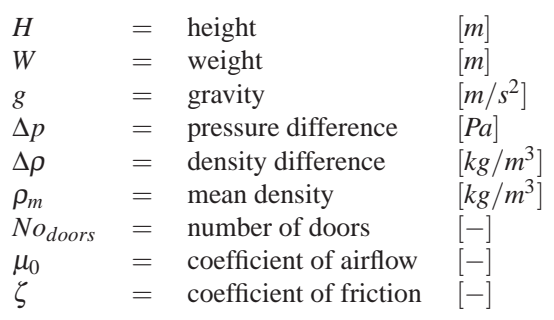

Air exchange between zone and ambient. Air exchange of a zone model and the ambient occurs due to variable indoor air pressure effected by internal temperature changes. This air exchange is inverse formulated, by setting the pressure difference to zero. The corresponding mass flow will be calculated by the model. This results in an efficient code that significantly reduces the computation time of an annual simulation.

Dynamic calculation of heat transfer coefficients for indoor and outdoor surfaces. Three calculation methods are implemented for the convective heat transfer. The first method describes the heat transfer coefficient as a constant parameter. The second method calculates the heat transfer coefficient depending on the temperature difference and the surface roughness. The third one defines the heat transfer coefficient depending on the temperature difference, the surface roughness, the wind speed, and the wind direction. The correlation of the second and third method are described in [1].

Window models with pre-designed window property records. The Window model considers two effects, the reflection of solar radiation and the thermal conductivity. The total solar gain through windows is considered by parameters based on the fraction of solar heat gain that passes through compared to either the incident solar radiation or the transmission of a reference glazing type. They are given as a decimal value in the range $0-1$. The HumanComfort library use the Solar Heat Gain Coefficient (SHGC) or the G-Value. 
Internal time table based heat source due to equipment and light sources. The influence of the variable operating time of the equipment is an important factor for the load and energy analyses calculations. The operating time can be set for every hour of a day. The following equation describes the implantation:

$$
\dot{Q}_{\text {equipment }}=\dot{Q}_{\text {heat_source }} \cdot f_{\text {time_table_equ }}
$$

$$
\begin{array}{llll}
\dot{Q}_{\text {heat_source }} & =\text { heat flow due to equipment } & {[W]} \\
\dot{Q}_{\text {equipment }} & =\text { total heat flow due to equipment } & {[W]} \\
f_{\text {time_table_equ }} & =\text { ratio of active equipment } & {[-]}
\end{array}
$$

Internal time table based heat- and water vapour sources due to occupants. The heat and vapour emission depends on the air temperature, the activity level, and the presence of the occupants. The InternalLoads model generates heat flow and humidity flow into the room. Eq. 23- 25 describe the correlation defined in [1].

$$
M E T=m e t \cdot A_{\text {skin }}
$$

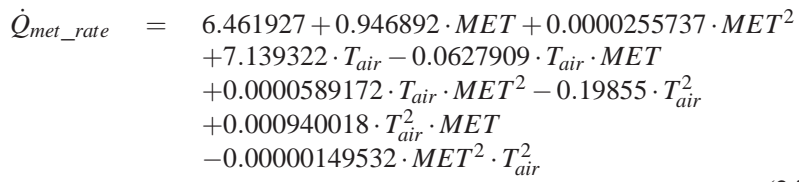

$\begin{array}{lll}\text { met } & =\text { spec. metabolic rate due to skin surface } & {\left[\mathrm{W} / \mathrm{m}^{2}\right]} \\ M E T & =\text { metabolic rate } & {[\mathrm{W}]} \\ A_{\text {skin }} & =\text { skin surface } & {\left[\mathrm{m}^{2}\right]} \\ \dot{Q}_{\text {met_rate }} & =\text { metabolic rate } & {[\mathrm{W}]} \\ T_{\text {air }} & =\text { indoor air temperature } & {\left[{ }^{\circ} \mathrm{C}\right]} \\ \dot{Q}_{\text {occupant }} & =\text { total heat prod. acc. to occupants } & {[\mathrm{W}]} \\ \text { occ } & =\text { number of occupants } & {[-]} \\ f_{\text {time_table_occ }} & =\text { ratio of present occupants } & {[-]}\end{array}$

[7] defines the vapour emission of the occupants depending on the air temperature and the activity as a matrix, see tab. 2.

\begin{tabular}{|c|c|c|c|c|c|c|c|}
\hline Air temperature & ${ }^{\circ} \mathrm{C}$ & $\mathbf{1 8}$ & $\mathbf{2 0}$ & $\mathbf{2 2}$ & $\mathbf{2 3}$ & $\mathbf{2 4}$ & $\mathbf{2 5}$ \\
\hline \hline$\dot{m}_{\text {vapor }}(120 \mathrm{~W})$ & $\mathrm{g} / \mathrm{h}$ & 35 & 35 & 40 & 50 & 60 & 60 \\
\hline$\dot{m}_{\text {vapor }}(190 \mathrm{~W})$ & $\mathrm{g} / \mathrm{h}$ & 95 & 110 & 125 & 135 & 140 & 145 \\
\hline$\dot{m}_{\text {vapor }}(270 \mathrm{~W})$ & $\mathrm{g} / \mathrm{h}$ & 165 & 185 & 215 & 225 & 230 & 240 \\
\hline
\end{tabular}

Table 2: Vapor emission of occupants depending on temperature and activity level defined by [7]

\section{Simplified}

HVAC

components. The HumanComfort library includes simplified HVAC components defined by [8](e.g. pump and radiator), which are compatible with the Modelica_Fluid library.
The radiator model consists of a control volume, a pressure drop model, and a heat transfer model. The input of the pressure drop model can be either a zeta value or a $K_{v}$ value. Two different heat transfer models are available and described in the following:

1. The heat flow is calculated by a heat transfer coefficient, the heat exchange surface, and the inbound water and air temperature difference. The model is discretized to increase the precission.

$$
\dot{Q}=k \cdot A \cdot\left(T_{\text {water }}-T_{\text {air }}\right)
$$

$$
\begin{array}{llll}
\dot{Q} & =\text { radiator heat flow to the room } & {[\mathrm{W}]} \\
k & =\text { heat transfer coefficient } & {\left[\mathrm{W} / \mathrm{m}^{2} \cdot K\right]} \\
A & =\text { heat transfer area } & {\left[\mathrm{m}^{2}\right]} \\
T_{\text {water }} & =\text { water temperature } & {[\mathrm{K}]} \\
T_{\text {air }} & =\text { air temperature } & {[\mathrm{K}]}
\end{array}
$$

2. The radiator heat flow is calculated by an approximating function, which uses a nominal characteristic of existent radiators. The input values for nominal conditions at the operating point are defined by radiator manufacturers. These values are available by using pre-designed records for severals radiator types.

$$
\begin{gathered}
\dot{m}_{n}=\frac{\dot{Q}_{n}}{\left(T_{\text {in }, n}-T_{\text {out }, n}\right) \cdot c p_{n}} \\
\Delta T_{m, n}=\frac{T_{\text {in }, n}+T_{\text {out }, n}}{2}-T_{\text {air }, n} \\
\left.\Delta T_{\max }=\max \left(\left(T_{\text {in }}-T_{\text {air }}\right)-\Delta T_{\text {out }, \text { min }}\right), 0\right) \\
\Delta T=\min \left(\frac{L \cdot\left(T_{\text {in }, n}-T_{\text {out }, n}\right) \cdot\left(T_{\text {in }}-T_{\text {air }}\right)}{T_{\text {in }, n}-T_{\text {air }, n}} \cdot \frac{\dot{m}_{n}}{\dot{m}}, \Delta T_{\text {max }}\right) \\
\Delta T_{m}=\max \left(\frac{T_{\text {in }}+\left(T_{\text {in }}-\Delta T\right)}{2}-T_{\text {air }}, 0\right) \\
f_{1}=\left(\frac{\Delta T_{m}}{\Delta T_{m, n}}\right)^{n_{\text {exp }}} \\
f_{5}=\left(\frac{p_{0}}{p_{\text {air }}}\right)^{0.75} \\
\dot{Q}=\dot{Q}_{n} \cdot \frac{L \cdot f_{1}}{f_{2} \cdot f_{3} \cdot f_{4} \cdot f_{5}}
\end{gathered}
$$

$\begin{array}{lll}\dot{Q}_{n} & =\text { nominal heat flow } & {[\mathrm{W}]} \\ \dot{m}_{n} & =\text { nominal mass flow } & {[\mathrm{kg} / \mathrm{s}]} \\ c p_{n} & =\text { nominal thermal capacity } & {[\mathrm{J} / \mathrm{kg} \cdot \mathrm{K}]} \\ T_{\text {in,n }} & =\text { nominal inbound water temperature } & {\left[{ }^{\circ} \mathrm{C}\right]} \\ T_{\text {out }, n} & =\text { nominal outbound water temperature } & {\left[{ }^{\circ} \mathrm{C}\right]} \\ T_{\text {air }, n} & =\text { nominal air temperature } & {\left[{ }^{\circ}\right]} \\ \dot{Q} & =\text { heat flow } & {[\mathrm{W}]} \\ \dot{m} & =\text { mass flow } & {[\mathrm{kg} / \mathrm{s}]} \\ T_{\text {in }} & =\text { inbound water temperature } & {\left[{ }^{\circ} \mathrm{C}\right]} \\ T_{\text {out }} & =\text { outbound water temperature } & {\left[{ }^{\circ}\right]} \\ T_{\text {air }} & =\text { air temperature } & {\left[{ }^{\circ} \mathrm{C}\right]} \\ \Delta T_{\text {m,n }} & =\text { mean nominal temperature difference } & {\left[{ }^{\circ} \mathrm{C}\right]} \\ \Delta T_{\text {max }} & =\text { maximal temperature difference } & {\left[{ }^{\circ} \mathrm{C}\right]} \\ \Delta T_{\text {out }, \text { min }} & =\text { minimal outlet temperature difference } & {\left[{ }^{\circ} \mathrm{C}\right]} \\ L & =\text { radiator length } & {[\mathrm{m}]} \\ n_{\text {exp }} & =\text { radiator exponent } & {[-]} \\ f_{1} & =\text { excess temperature factor } & {[-]} \\ f_{2} & =\text { temperature splay factor } & {[-]} \\ f_{3} & =\text { correction factor - type of connection } & {[-]} \\ f_{4} & =\text { correction factor - type of cover } & {[-]} \\ f_{5} & =\text { correction factor - atmospheric pressure } & {[-]}\end{array}$




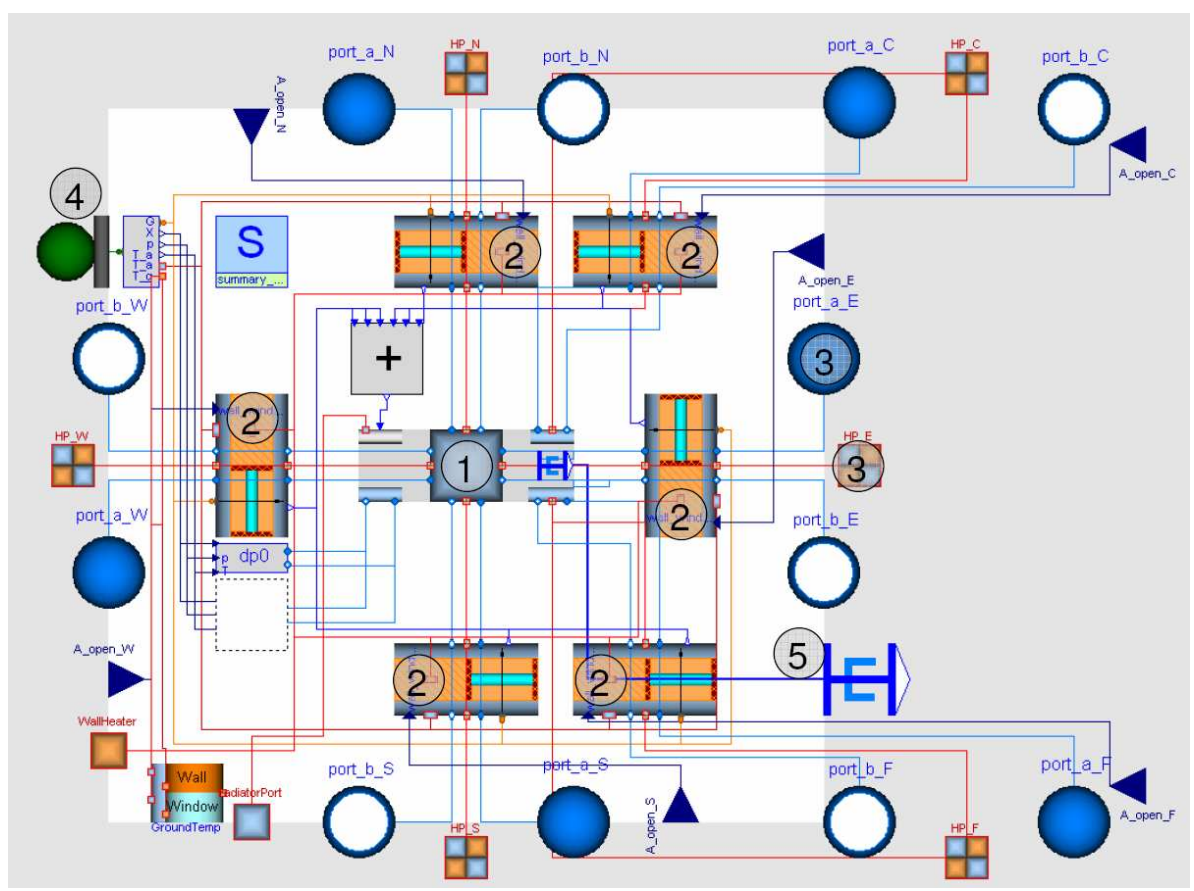

Figure 9: Diagram layer of the room model

Mean radiant temperature. Three different functions are implemented to calculate the mean radiant temperature of a cubical room with six sides.

1. The mean_T_MRT function sets the mean surface temperature to the mean radiant temperature [1].

$$
T_{M R T}=\frac{\sum_{i=1}^{x} T_{i}}{x}
$$

2. The mean_T_to_A_MRT function calculates surface weighted mean radiation temperatures [1].

$$
T_{M R T}=\frac{\sum_{i=1}^{x} A_{i} \cdot T_{i}}{A_{\text {Total }}}
$$

$$
\begin{array}{ll}
T_{M R T} & =\text { Mean Radiant Temperature } \\
T & =\text { Temperature } \\
A & =\text { Area }
\end{array}
$$

3. The deltaT_max_MRT function calculates the mean radiation temperature depending on the mean surface temperature and the temperature that has the highest difference to the mean value $T_{\max , \text { dif }}$. The HumanComfort library use $T_{\max , \text { dif }}$ as an extreme value, because normally the surface that is next to the occupant would be used as the maximal value. But the model has no geometric data of the position of the occupant so the maximal possible value will be used.

$$
T_{M R T}=\frac{T_{\max , \text { dif }}+T_{\text {mean }}}{2}
$$

Fig. 9 shows a main model of the zone package, the room model. It consists, amongst others, an air control volume (1), a radiation exchange model (1), internal heat and vapour sources (1), six multi-layer wall models (2), several heat and fluid connectors (3), a weather connector (4), and a human comfort adapter (5).

\section{Weather}

The weather package provides severals ambient conditions by reading an external text file.

- Ambient and temperature, pressure and humidity

- Global, direct and diffuse radiation to a tiled surface

- Azimuth (north based) and Zenith

- Sun position and radiation, depending on the location

\section{Verification and Validation}

An essential part of the library development is the verification and validation. The verification process of the HumanComf ort models and functions was done in accordance with the implemented standards.

A comparative validation test was done by comparing the HumanComfort library with the EnergyPlus/DesignBuilder program [1], which is validated according to ANSI/ASHRAE Standard 140-2004. 
Therefore a two room test model was established (see fig. 10).

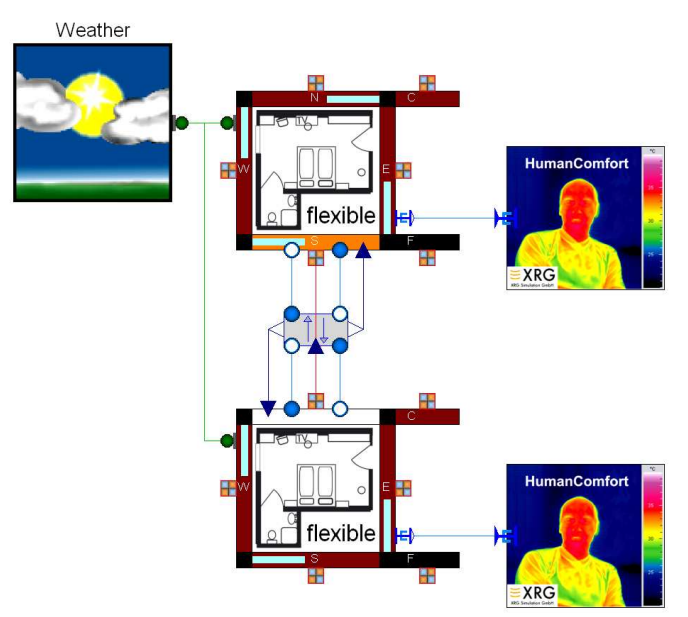

Figure 10: Graphical representation of the HumanComfort test model for the validation

The rooms have an opening in the adjacent wall to consider an air exchange. No heating system was implemented to generate higher temperature differences between the rooms. The rooms have one occupant with a normal metabolic rate for office activities (1met). The north room has two windows, one orientated to the west and one to the east. The south room has one window orientated to the south. The ambient condition are defined by the weather data, which references to the city of Hamburg. The graphical representation of the two room test model is shown in fig. 11.

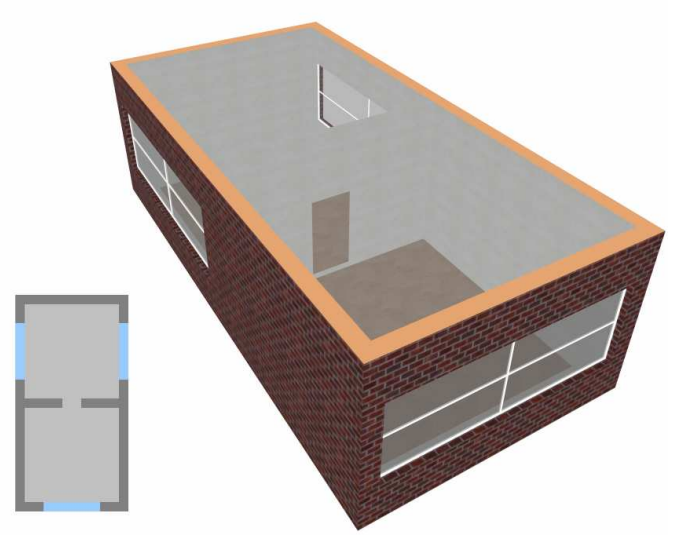

Figure 11: Graphical representation of the DesignBuilder test model for the validation

As the operative, mean radiant, and the indoor air temperature were important factors for thermal comfort, their simulation results will be discussed. Fig. 12 shows the simulation results of the north room operative and outside temperature over a time period of one year.

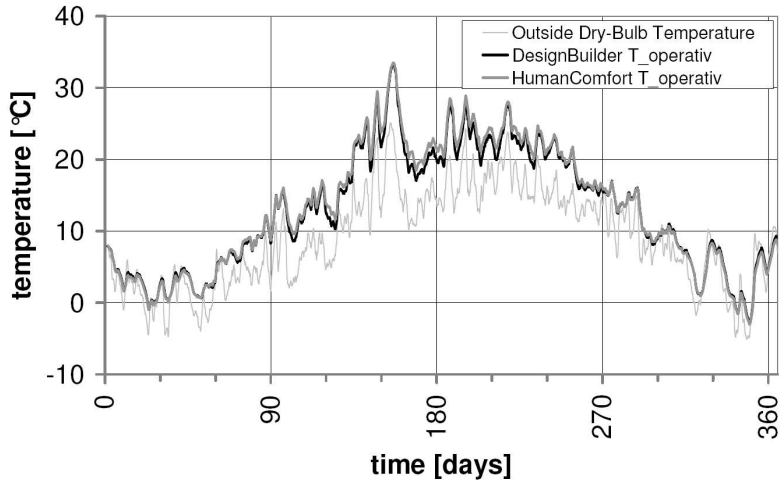

Figure 12: Simulation results of the operative and outside temperature from the HumanComfort library and DesignBuilder of the north room

Tab. 3 shows the mean values of the different temperatures, the deviation to each other and the mean of the absolute deviations.

\begin{tabular}{|l|c|c|c|c|}
\hline mean value & HC & DB & dev. & abs. dev. \\
\hline \hline unit & ${ }^{\circ} \mathrm{C}$ & ${ }^{\circ} \mathrm{C}$ & ${ }^{\circ} \mathrm{C}$ & ${ }^{\circ} \mathrm{C}$ \\
\hline \hline indoor temperature & 13.058 & 12.633 & 0.425 & 0.625 \\
\hline operative temperature & 13.215 & 12.816 & 0.399 & 0.611 \\
\hline mean radiant temperature & 13.372 & 13.000 & 0.372 & 0.620 \\
\hline
\end{tabular}

Table 3: Selected temperatures of the north room

The maximum deviations occurs in the summer during rapidly decreasing outside temperatures. The mean deviation of the operative temperature amounts to $0.399^{\circ} \mathrm{C}$ with an absolute deviation of $0.611^{\circ} \mathrm{C}$. The mean deviation of the indoor air temperature amounts to $0.425^{\circ} \mathrm{C}$ with a maximal deviation of $2.4^{\circ} \mathrm{C}$ at 11 th of June.

Fig. 13 depicts the relative humidity of the north room during the course of the year. The occurring deviations can be explained by the fact that the relative humidity depends on the temperature.

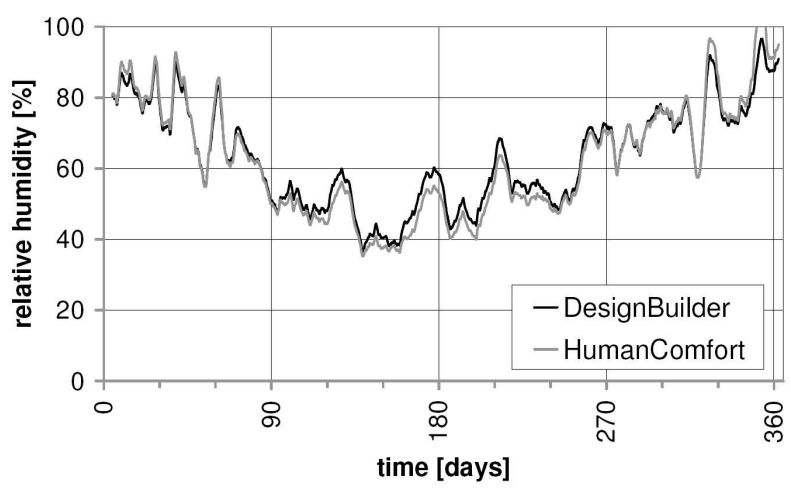

Figure 13: Simulation results of the relative humidity 
The resulting PMV of the north room is shown in fig. 14. Due to the fact that the PMV depends on the temperature and relative humidity the deviations behave analogous.

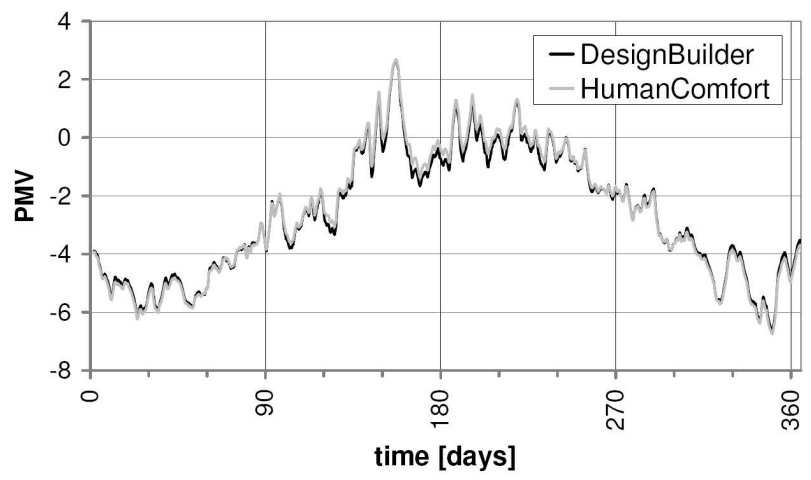

Figure 14: Simulation results of the PMV from HumanComf ort library and DesignBuilder of the north room

Tab. 4 displaces the mean values of the PMV, the deviation to each other and the mean of the absolute deviations.

\begin{tabular}{|l|c|c|c|c|}
\hline mean values & HC & DB & deviation & absolute dev. \\
\hline \hline PMV & -2.62 & -2.67 & -0.047 & 0.151 \\
\hline
\end{tabular}

Table 4: Mean values and their deviations of the PMV from the north room

The comparative validation test reveals that the results predicted by the HumanComfort library are within the range of EnergyPlus/DesignBuilder.

\section{Conclusion}

The HumanComfort library enables the prediction of thermal comfort in zone models. All relevant characteristic numbers, described in the standards, are implemented. The validations shows that the stationary zone model is in the range with another accurate energy simulation program on the market. The library development is still going on. The complete implementation of the mobile application will be finished until the end of the EuroSysLib-D project.

\section{Acknowledgement}

The HumanComfort library is developed within the European research project EuroSysLib-D funded by German Federal Ministry of Education and Research (promotional reference 01IS07022B). The project has been started in October 2007 and will end in March 2010. The authors bear the sole responsibility for the content of this publication.

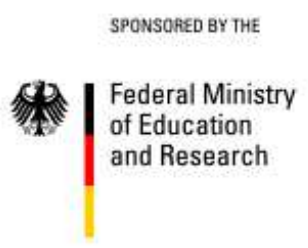

\section{References}

[1] US Department of Energy. EnergyPlus - Engineering Reference, June 2007.

[2] DIN EN ISO 7730. Ergonomics of the thermal environment - Analytical determination and interpretation of thermal comfort using calculation of the PMV and PPD indices and local thermal comfort criteria. Beuth Verlag GmbH, 2005.

[3] ASHRAE Standard 55-2004. Thermal Environmental Conditions for Human Occupancy, January 2004.

[4] A.C. van der Linden A.C. Boerstra W. Plokker A.K. Raue, S.R. Kurvers. Dutch Thermal Comfort Guidelines from Weighted Temperature Exceeding Hours Towards Adaptive Temperature Limit, 2004.

[5] Strand Pedersen. Modeling Radiant Systems in an Integrated Heat Balance Based Energy Simulation Program. ASHRAE Transactions, 2002.

[6] Frank Meyer zur Heide. Energieeinsparung und Komfortgewinn. CCI Print, 2005.

[7] Schramek Recknagel, Sprenger. Taschenbuch für Heizung und Klimatechnik. Oldenbourg Industrieverlag, 2005.

[8] Bernd Glück. Strahlungsheizung - Theorie und Praxis. C.F. Müller Verlag Heidelberg, 1982. 